\title{
Caribbean Indian
}

National Cancer Institute

\section{Source}

National Cancer Institute. Caribbean Indian. NCI Thesaurus. Code C77810.

Denotes a person having origins in one of the indigenous people of the Caribbean. 